
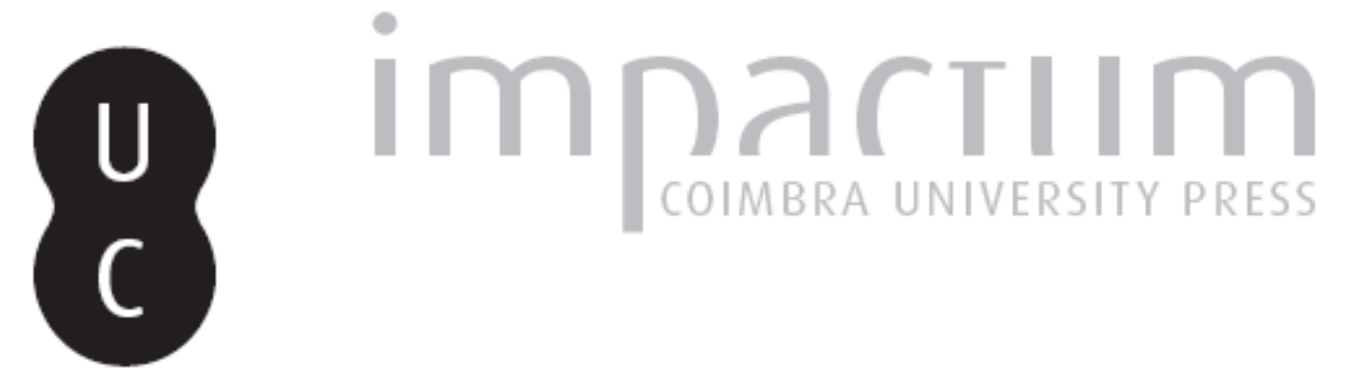

\title{
A campanha militar de Ceuta (1415) revisitada
}

Autor(es): $\quad$ Monteiro, João Gouveia

Publicado por: Imprensa da Universidade de Coimbra

URL persistente:

URI:http://hdl.handle.net/10316.2/43327

DOI:

DOI:https://doi.org/10.14195/1645-2259_17_3

Accessed : $\quad$ 26-Apr-2023 14:31:23

A navegação consulta e descarregamento dos títulos inseridos nas Bibliotecas Digitais UC Digitalis, UC Pombalina e UC Impactum, pressupõem a aceitação plena e sem reservas dos Termos e Condições de Uso destas Bibliotecas Digitais, disponíveis em https://digitalis.uc.pt/pt-pt/termos.

Conforme exposto nos referidos Termos e Condições de Uso, o descarregamento de títulos de acesso restrito requer uma licença válida de autorização devendo o utilizador aceder ao(s) documento(s) a partir de um endereço de IP da instituição detentora da supramencionada licença.

Ao utilizador é apenas permitido o descarregamento para uso pessoal, pelo que o emprego do(s) título(s) descarregado(s) para outro fim, designadamente comercial, carece de autorização do respetivo autor ou editor da obra.

Na medida em que todas as obras da UC Digitalis se encontram protegidas pelo Código do Direito de Autor e Direitos Conexos e demais legislação aplicável, toda a cópia, parcial ou total, deste documento, nos casos em que é legalmente admitida, deverá conter ou fazer-se acompanhar por este aviso.

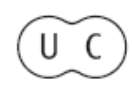




\title{
A Campanha Militar de Ceuta (1415) Revisitada The Military Campaign of Ceuta (1415) Revisited
}

\author{
João Gouveia Monteiro \\ Centro de História da Sociedade e da Cultura \\ Centro de História da Universidade de Lisboa \\ joao.g.monteiro@sapo.pt
}

Texto recebido em/Text submitted on 24/11/2016 Texto aprovado em /Text approved on 15/03/2017

Resumo: Este artigo procura revisitar os aspetos militar relacionados com a conquista portuguesa da praça norte-africana de Ceuta, no verão de 1415 . Os ângulos de abordagem considerados são seis: i) a planificação estratégica da campanha; ii) o recrutamento de gentes de armas para integrarem a frota; iii) o financiamento da campanha; iv) a dimensão da logística envolvida; v) o armamento individual; vi) por fim, a planificação e execução tática da campanha, o aspeto que merece uma reapreciação mais demorada e problematizadora ao longo deste texto.

Palavras-chave: Ceuta, guerra medieval, D. João I.

Abstract: This article tries to revisit the military aspects related to the Portuguese conquest of the North African city of Ceuta, in the summer of 1415. The approach angles considered are six: i) the strategic planning of the campaign; ii) the recruitment of warriors to join the fleet; iii) the financing of the campaign; iv) the bulk of the logistics involved; v) individuals arms and armour; vi) finally, the tactical planning and execution of the campaign, the aspect that deserves a more time-consuming and problematizing review throughout this text.

Keywords: Ceuta, medieval warfare, King John I ${ }^{\text {st }}$.

O sexto centenário da conquista de Ceuta, celebrado em 2015, constituiu um tempo de muitas lições ministradas por historiadores, de muitas evocações e de muitos colóquios e livros, mas foi também um tempo de grandes lições para os historiadores e para a comunidade científica em geral: quem esperaria um tal entusiasmo por este acontecimento singelo da nossa história? Quem adivinharia, um ou dois anos antes, uma tamanha mobilização de atenções por parte da imprensa escrita e falada, com o epicentro do fenómeno a ser registado nos dias 21 e 22 de agosto de 2015? Poucas evocações da história portuguesa suscitaram um interesse tão grande dos media e do público em geral, ao longo das últimas décadas. $\mathrm{E}$ ainda bem que assim foi, embora estejamos conscientes de que terá sido a circunstância de, no nosso imaginário coletivo, a tomada de Ceuta ser vista como o tiro de partida para o período de ouro da História de Portugal (uma interpretação que está hoje distante de gerar consenso entre os historiadores) que, em boa medida, se encontrou por detrás do regozijo nacional com que a data foi recordada. 
Seja como for, não restam dúvidas de que a operação de 1415 constituiu um marco importantíssimo da nossa história secular e ainda bem que ela tem sido evocada, sob diversos ângulos, muito interessantes e complementares. Recordo, a título de exemplo, os grandes congressos organizados pela Academia da Marinha, pela Sociedade Portuguesa de Estudos Medievais e pelo Instituto de Estudios Ceutíes, assim como o rico ciclo temático de conferências "As décadas de Ceuta (1385-1460)", realizado na Universidade Autónoma de Lisboa entre outubro de 2015 e maio de 2016, sob a coordenação científica dos Senhores Professores Doutores Maria Helena da Cruz Coelho e Armando Luís de Carvalho Homem. Gostaria de regressar ao tema que desenvolvi neste último evento científico, revisitando e reapreciando os aspetos estritamente militares da conquista da primeira praça ultramarina portuguesa. Para este efeito, decidi eleger seis ângulos de abordagem da maior operação militar da nossa história medieval.

Falarei, em primeiro lugar, da planificação estratégica da campanha, que é talvez o aspeto que mais me impressiona em toda esta evocação. Não conheço nenhuma outra operação medieval portuguesa que tenha sido preparada com tanta antecedência e com tanto cuidado. D. João I deve ter começado a pensar seriamente na empresa logo após a assinatura da paz com Castela, em outubro de 1411 (não acredito que o possa ter feito muito antes, tal era o risco de pôr em causa um esforço de décadas de consolidação no poder e de afirmação da dinastia avisina). Num tempo em que não havia ainda exércitos permanentes (que, após o desaparecimento das legiões romanas, só reaparecem na cena europeia em meados do século XV, com as «Companhias de Ordenança» do rei Carlos VII de França), quatro anos para preparar uma operação militar era um luxo absolutamente singular.

Para mais, o monarca português - tudo o indica - tratou de manter o projeto o mais possível em segredo, partilhando-o apenas com os filhos mais velhos e com um escol de colaboradores e de altos funcionários da cúria régia, tendo mesmo evitado convocar as cortes para conseguir autorização para o lançamento de um imposto extraordinário que, segundo a prática costumeira, viabilizasse a cobrança de recursos para preparar a expedição.

Em síntese, tudo foi feito com muito tempo, na maior discrição e com um grau de exigência e de profissionalismo exemplares. Isto implicou mesmo uma rocambolesca operação de espionagem da praça magrebina, interpretada pelo prior do Hospital (Álvaro Gonçalves Camelo) e pelo capitão-mor da frota (Afonso Furtado), a pretexto de uma missão diplomática na Sicília, creio que concretizada no verão de 1412 (M. Henr, II, 10: 49-50, n. 1). O estudo sobre como atacar a Ceuta merínida teve, assim, direito a uma maqueta de arquiteto, improvisada nos aposentos régios com meio alqueire de favas, um novelo de fita, duas cargas de areia e uma escudela, materiais com que se produziu uma 
réplica da cidade, com as suas muralhas e torres, os seus terrenos e declives e os ancoradouros mais propícios a um futuro desembarque dos cristãos (Zurara, C.T. Ceuta, XV-XVIII: 48-59) ...

Como se não bastasse, D. João I - monarca assaz astuto e experiente nas coisas da guerra - tratou ainda de organizar manobras de diversão visando distrair as atenções dos reinos ibéricos (e não só) acerca dos verdadeiros motivos e alvos da campanha. É aqui que podemos incluir a rábula organizada com a cumplicidade do «duque da Holanda» (provavelmente o duque da Zelândia), a pretexto de vingar algumas afrontas sofridas por embarcações mercantis portuguesas que costumavam navegar por águas da Frísia e do Mar do Norte. É impressionante a descrição que Gomes Eanes de Zurara - de longe a nossa fonte mais importante (e, a meu ver, uma fonte globalmente credível) - faz acerca do aturdimento dos reinos vizinhos com o que estava a preparar-se em Portugal (id., XXXI-XXXIV: 97-109). Daí resultou, como se sabe, o envio de espiões desses monarcas para Lisboa, com o fito de tentarem perceber o que é que realmente estava a acontecer em Portugal. É aqui que se enquadra a presença do castelhano Rui Díaz de Vega em Lisboa, a partir de abril de 1415, e o detalhado relato que ele enviou ao seu senhor, o rei Fernando I de Aragão. Para grande fortuna nossa, essas missivas sobreviveram e constituem uma fonte de excecional importância para a reconstituição dos aspetos militares da campanha. Com todas as suas limitações (por exemplo, dificuldade em destrinçar claramente entre as várias categorias de besteiros que a Coroa mobilizava: do conto, de quantia, de cavalo), Rui Díaz fornece-nos, em carta datada de 23 de abril de 1415, dados muito interessantes sobre o número de barcos, sobre as tripulações, sobre os soldos, sobre os materiais instalados a bordo e sobre vários outros aspetos relevantes da campanha (M. Henr., II, 57: 132-146).

O meu segundo ângulo de observação diz respeito ao recrutamento de gentes de armas para integrarem a frota. Como tenho sublinhado ao longo do último quarto de século, no Portugal dos finais da Idade Média uma hoste régia era formada por uma soma de parcelas com proveniências distintas e claramente identificáveis: a nobreza contribuía com um número significativo de "lanças", que eram essenciais por constituírem o núcleo duro do exército e praticamente o único que tinha formação militar; as Ordens Militares acrescentavam a esse pecúlio os seus (relativamente magros) contingentes de homens de armas, geralmente bastante eficientes e disciplinados; a população concelhia (gente da lavoura ou dos mesteres) garantia o grosso da 'carne para canhão', através do sistema dos «aquantiados» e dos «besteiros do conto», já para não falar na milícia (algo híbrida, porque recrutada no universo concelhio mas elevada ao estatuto de vassalidade régia) dos «besteiros de cavalo»; finalmente, acrescentavam-se a estas parcelas mercenários contratados no exterior (em 
número habitualmente reduzido: algumas centenas, na melhor das hipóteses) e, por vezes, pequenos contingentes de homiziados que cumpriam penas longas em lugares inóspitos e a quem era prometida uma comutação ou mesmo um perdão de pena, caso integrassem a hoste régia (Monteiro 1998: 27-134).

Não sabemos ao certo quantos combatentes integraram a armada que conquistou Ceuta em 1415. O espião Rui Díaz de Vega fala em 18600 a 19000 combatentes, entre os quais 4685 vassalos régios (incluindo 700 que haviam sido feitos de novo), 1900 besteiros a cavalo (munidos das suas armas e bestas), 3000 outros besteiros (sem armas), 4000 peões munidos de escudos e 5000 lanceiros (M. Henr., II, 57: 132-146) ${ }^{1}$. Para fornecer esta estimativa ao rei de Aragão, o espião alega ter consultado pessoalmente os livros das apurações, ou seja, os cadernos que continham os registos resultantes dos alardos e das convocatórias ordenadas pelos anadéis e coudéis do reino, isto é, pelos oficiais responsáveis pela mobilização militar da população concelhia. Pelo seu lado, o alferes-mor do reino, João Gomes da Silva, numa carta que dirigiu ao arcebispo de Santiago (de quem parece ter sido amigo) na hora da partida da frota do Restelo, afirma que a armada se compõe de 270 velas, galés e outras fustas mais pequenas, que levam a bordo 7000 a 7500 homens de armas, 5000 besteiros e até 20000 ou 21000 homens de pé, ou seja, entre 32000 e 33500 combatentes (M. Henr. II, 68: 64).

Convém recordar que, graças a uma preciosa indicação de Fernão Lopes inserta no antepenúltimo capítulo da Segunda Parte da Crónica de D. João I, sabemos que, nos inícios do século XV, aproveitando a bonança que havia nas relações com Castela (porventura após a celebração das tréguas luso-castelhanas por 10 anos ratificadas em Santarém em 1402, ou então logo a seguir à paz de 1411), o conselho régio joanino decidiu fixar uma "hordenança certa pera deffenssam de seus reinos, de tres myl e duzemtas lamças” (Lopes, C.D.J., II, CCII: 453-454). Destas, 500 "lanças" (combatentes completamente equipados) deveriam ser fornecidas pelo núcleo restrito (uma ou duas dezenas, no máximo) dos principais vassalos do reino (os chamados «capitães»), enquanto os pequenos vassalos (oriundos da pequena nobreza ou nem isso) deveriam garantir 2360 "escudeiros de huma lança", cabendo as restantes 340 lanças às Ordens Militares: 100 a cargo do Mestre de Cristo e dos seus comendadores, $100 \mathrm{sob}$ a responsabilidade do Mestre de Santiago, 80 por conta do Mestre de Avis e, finalmente, 60 pelas mãos do Prior do Hospital. Em síntese, o nosso esboço de 'primeiro exército fixo de defesa' incluiria uma fina-flor de 320 dezenas de homens de armas convenientemente equipados e, muitos deles, montados, dos quais $15,62 \%$ seriam assegurados pelos grandes fidalgos (que recebiam "contias" anuais mais chorudas), $73,75 \%$ pela vassalagem miúda registada no «Livro dos Vassalos» e 10,62\% pelas Ordens Militares.

\footnotetext{
Veja-se também Monteiro e Costa 2015: 37; e Duarte 2015: 168.
} 
Também sabemos, graças ao arrolamento dos besteiros do conto de 1421 incorporado nas Ordenações Afonsinas, que nesta data a organização militar do reino previa a existência de perto de 5000 besteiros do conto (geralmente mesteirais) distribuídos por um pouco mais de 300 unidades de recrutamento, entre cidades, vilas, julgados, coutos, honras, terras das Ordens Militares e terras chãs (O. Af., I, LXIX: 437-447). Quanto aos besteiros de cavalo, julgo ter demonstrado que se tratava de uma milícia restrita, um escol criado em 1392, com 500 atiradores distribuídos pelo reino e colocados sob a tutela de um capitão e coudel-mor chamado Álvaro Anes de Cernache (Monteiro 1998: 72-73). Já no que diz respeito aos «aquantiados», ou seja, aos moradores do reino (com exceção dos clérigos, dos fidalgos e dos vassalos do rei) que mantinham casa própria e cuja fortuna pessoal era regularmente avaliada de modo a inseri-los num determinado escalão a que correspondiam obrigações próprias em matéria de posse de cavalos e/ou armas, é impossível calcular com exatidão o seu número potencial de efetivos, que rondaria talvez os 10000 ou mais (id.: 49 e 91).

Assim, ao tempo de Ceuta, a realeza poderia contar, em condições ideais, com até cerca de 20000 combatentes, dos quais 5000 ou 6000 a cavalo e sete ou oito milhares de atiradores. Mas, para tanto, era preciso que a mobilização fosse intensiva e exaustiva (cobrindo todas as comarcas do reino), fosse feita com larga antecedência e (ao contrário do que aconteceu em Aljubarrota, por exemplo) recaísse sobre um país não dividido internamente e que estivesse fortemente galvanizado em torno de um projeto 'nacional'. Provavelmente, terá sido justamente isto que sucedeu em 1415, pois parece inegável o entusiasmo que a expedição suscitou e a antecedência e os cuidados mil com que foi preparada. De Inglaterra, de França (nomeadamente da Gasconha e da Picardia) e também da Alemanha acorreram alguns homens de armas a juntar-se à frota que se preparava sobretudo em Lisboa e no Porto (Duarte 2015: 167). É praticamente certo que, apesar da coincidência com a campanha de Harfleur-Agincourt, pelo menos um capitão inglês, chamado Edmund Arnald (um empresário da Gasconha sedeado em Dartmouth), agindo como capitão mercenário por sua conta e risco, participou na campanha portuguesa de 1415 com quatro ou cinco navios mercantes adaptados a navios de combate, a bordo dos quais seguiam muitos arqueiros e outros combatentes, em número indeterminado (Faria in Monteiro et al. 2017)2. Aliás, no citado relatório enviado a Fernando I de Aragão, o agente Rui Díaz de Vega menciona a presença no rio Tejo de 10 navios ingleses (oito naus e duas barcas mercantis), somando 850 toneladas, os quais estavam preparados para integrar a expedição levando, cada qual, a bordo 20 homens.

Sobre as relações luso-inglesas na época da expedição a Ceuta, veja-se também Faria 2013; e, claro, o estudo clássico (1955) e ainda insubstituível de Russell 2000. 
Tendo tudo isto em conta, e não ignorando as isenções, deserções e outras falhas que o sistema de mobilização militar tardo-medieval português comportava, parece-nos legítimo admitir que a armada que partiu do Restelo a 24 de julho de 1415 tivesse reunido muito perto do máximo que era então possível mobilizar de gentes, talvez em número de 18000 a 20 000, eventualmente transportadas em cerca de duas centenas de navios (para os barcos, cf. Duarte 2015: 69). Devemos, no entanto, admitir que, entre aquela gente, figurasse um número não despiciendo (10 a 15\%) de não combatentes (pessoal auxiliar, serviçais, homens dos mesteres), pelo que a cifra 'útil' de combatentes efetivos deveria ser mais reduzida. No total, e considerando também a indicação do espião aragonês de que teriam sido então feitos muitos vassalos novos (o que não nos custa admitir, tendo em conta aquilo que sabemos sobre o modo de proceder de $\mathrm{D}$. João I em tempo de guerra), talvez não seja exagero pensar em 3500 lanças da pequena, média e alta nobreza, das Ordens Militares e da guarda do rei, perto de 4000 besteiros, cerca de 7500 aquantiados e 1000 outros homens de armas, entre mercenários e homiziados. Um número impressionante para um reino que teria então cerca de um milhão e meio de habitantes e que vivia - financeiramente falando - dias muito difíceis.

Só o grande entusiasmo pela campanha (ainda que esta fosse de destino incerto) e a antecedência inédita com que ela foi lançada podem explicar uma tal mobilização. Zurara dá claramente conta dos esforços feitos pelos infantes para reunirem os coudéis e os anadéis das comarcas e desencadearem uma mobilização maciça dos homens por eles tutelados (C. T. Ceuta, XXIX: 88); e explica mesmo que foi ordenado ao escrivão da puridade, Gonçalo Lourenço de Gomide, que mandasse fazer cartas em nome do rei para serem enviadas a todos os oficiais, coudéis e anadéis, mandando-lhes que organizassem de imediato os seus alardos e que enviassem depois para a corte os respetivos cadernos, com a indicação exaustiva dos nomes, das idades e do equipamento dos homens disponíveis para servirem na campanha de Ceuta (id., XXI: 66-67). Também sabemos ter sido providenciado o pagamento dos soldos e das «contias» anuais que eram devidas aos vassalos e a todas as pessoas que a tal tinham direito, tendo D. João I enviado "cartas de percebimento" aos senhores, aos fidalgos e aos homens de conta, para que se aprestassem a ir na armada e para que lhe mandassem dizer urgentemente com quanta gente sua (isto é, com quantos homens recrutados nas suas terras e senhorios) tencionavam servi-lo naquela aventura, de maneira a que o monarca pudesse rapidamente reunir a verba necessária ao pagamento dos respetivos soldos (id., XXIX-XXX, pp. 88-90). O espião aragonês explica até que os homens de armas portugueses receberiam 700 libras ao mês, enquanto os besteiros principais teriam direito à mesma coisa e os restantes atiradores e homens de pé a 400 libras; e acrescenta que o soldo das fustas estava pago com um adiantamento de cinco semanas e 
que os vassalos tinham recebido as suas quantias de 1414 e de 1415 (M. Henr., II, 57: 136).

Aqui chegados, toco já no terceiro ângulo da minha revisitação - o do financiamento da campanha. De facto, a inusual decisão de evitar a convocação das cortes para reunir a verba necessária a tamanho empreendimento implicou uma série de medidas extraordinárias, de que destacaremos: uma desvalorização monetária (mais uma!), com a cunhagem, de dia e de noite, de reais brancos novos nos fornos a cargo de Rui Pires do Alandroal, o tesoureiro da moeda (Zurara, C. T. Ceuta XXI: 66-67); a afetação das valiosas rendas de Lisboa à expedição; a requisição compulsiva de bens alimentares e de equipamentos nas grandes cidades, em especial na capital, que terá ficado muito "gasta" de pão e de mantimentos, ao ponto de o monarca decidir conceder isenção do pagamento da dízima e da sisa aos mercadores que importassem ou que trouxessem por mar os cereais e os legumes de que Lisboa tanto precisava ${ }^{3}$; a imposição aos grandes fidalgos que não fossem na armada do pagamento de um marco de prata (caso dispusessem de uma «contia» superior a 100000 libras), ao passo que os sete bispos do reino teriam de emprestar 50 marcos, os arcebispos (de Braga e de Lisboa) o dobro dessa verba, e os clérigos ricos de igreja deveriam empenhar-se em recolher o mais que conseguissem junto dos cidadãos abastados das suas áreas de intervenção (M. Henr. II, 57: 136); quanto aos homens comuns que não fossem mobilizados para a campanha, teriam de emprestar armas e bestas àqueles que partiam na armada, comprometendo-se estes a devolver-lhas em bom estado no prazo de dois meses contado a partir do regresso da frota. Também as comunas de mouros e de judeus foram oneradas com grandes cobranças em prata, tal como refere o citado relato de Rui Díaz de Veja; foi ainda lançada uma requisição compulsiva de sal aos produtores, com vista ao pagamento de uma parte significativa dos navios estrangeiros envolvidos na operação. Em tudo isto foram decerto cometidos muitos abusos (c. exemplos em Monteiro e Costa 2015: 31-32), justificados com os nobres objetivos da expedição, que Jorge de Faro (1965: 66) calculou ter custado ao reino um total de 280000 dobras.

Neste enorme esforço organizativo, impressiona também a dimensão da logística envolvida - o quarto ângulo de análise que escolhi. Em minha opi-

\footnotetext{
Cf. Braga e Braga 1998: 18-19; temos registo de tais isenções para os anos de 1413, 1414 e 1415. A título ilustrativo, lembrem-se também as reclamações apresentadas em cortes, nos anos a seguir à expedição; por exemplo, nas Cortes de Lisboa de 1439, os procuradores de Garvão alegaram junto do Regente (o infante D. Pedro) que D. João I tinha lançado naquele lugar, aos lavradores que os possuíam, certo trigo e cevada para Ceuta, bens esses que nunca lhes tinham chegado a ser pagos (IHES, FLUC, Col. Cortes, Cortes de Lisboa de 1439, Capítulos Especiais de Garvão, n.o 2, fls. 160v.o-161). Já depois da finalização deste artigo, ocorreu a publicação das Cortes de 1439, do que damos conta na bibliografia final deste trabalho.
} 
nião, as páginas mais belas da crónica de Zurara dizem precisamente respeito ao fervor com que foram assumidos, um pouco por todo o reino mas sobretudo nas regiões de Lisboa e do Porto, os preparativos da expedição: alfagemes a limpar armas; homens e mulheres comuns a fazer biscoito e a salgar enormes quantidades de carne e de outras vitualhas; marinheiros a correger navios e a aparelhar guarnições; calafates e mesteirais a acabar e a embelezar as naves estacionadas no rio Tejo; carniceiros a decepar vacas e bois, a esfolar os animais, a cortá-los e a salgá-los, enfiando-os depois nos tonéis e nas "botas" onde haveriam de ser transportados; pescadores e suas mulheres a abrir e a salgar pescadas, cações e raias espalhados ao Sol; tanoeiros a reparar vasilhas para transporte de vinhos, de toucinho, de azeite, de vinagre, de carnes e de peixes secos e salgados, entre muitas outras vitualhas; alfaiates e tosadores a fabricar e a engalanar as primeiras librés de guerra de que temos notícia; carpinteiros a encaixar os trons e as bombardas nos seus reparos e a cuidar da engenharia neurobalística (em grande quantidade e de grande dimensão) que seria necessário instalar para armar o cerco; cordoeiros a compor guindastes, cabos e outra cordoaria de linho; entre outros aspetos (C. T. Ceuta, XXX: 90-93).

Foram dezoito meses de grande afã logístico, que permitiram que a frota levasse a bordo, não apenas mantimentos para muitos dias (Rui Díaz explica que os mais ilustres levavam comida para três meses $)^{4}$, mas também um material de assédio impressionante, que além dos trons e das bombardas incluía as peças necessárias para no local se poder montar um palanque de madeira, dois engenhos de arremesso de pedras (em minha opinião, provavelmente trabucos de tração humana), diversas escadas de assalto e uma sólida torre móvel de madeira forrada de guardas de alcornoco (para dificultar a combustão), com 28 braças de altura, cinco sobrados de madeira e as rodas necessárias para permitir a aproximação às muralhas de Ceuta ${ }^{5}$ Com estas peças seguia uma vasta panóplia de ferramentas, como por exemplo machados, enxadões, pás, martelos, pregos e tudo o mais que era comum nestas ocasiões. Ao que parece, a supervisão desta componente de logística militar da campanha terá ficado a cargo do monarca (Zurara, C. T. Ceuta, XXIX: 89).

A talho de foice, devemos apreciar agora o armamento individual (o quinto ângulo da minha observação), que em grande medida seria trazido de casa pelos próprios combatentes, como era ainda tradição nesta época: no mesmo documento (de março de 1414) em que D. João I renova a antiga regra de ninguém (mestres de navios, marinheiros ou senhores, em especial os de Lisboa) poder

4 Cf. M. Henr. II, 57: 135-136: "Cada uno que lyeve pera cada ome tres fanegas de pan cocho [biscoito] et tres cantaras et medja de vjno et su carne et pescado, en tal manera que lyeven complymento de tres meses”.

5 Sobre estes engenhos, em especial sobre o «castelo de madeira», vejam-se as reflexões de Duarte 2015: 82. 
fretar barcos para levarem castanhas, avelãs, nozes e outros mantimentos a terra de mouros, insiste-se também na proibição do comércio de lanças, de dardos, de espadas, de solhas, de bacinetes, de cotas de malha, de bestas e até de ferro ou aço com os infiéis, tudo isto sob pena de morte e de confisco e repartição dos respetivos navios entre a Coroa e os acusadores (Chanc. Port., D. João I, vol. III, t 3: 162-163, de 23-03-1414).

Mas há também numerosas referências ao confisco de arneses (a mais completa e sofisticada proteção de tronco e de membros dos finais da Idade Média), designadamente no contexto de reuniões de cortes realizadas muito depois da expedição. Por exemplo, na assembleia celebrada em Lisboa, em 1427, os procuradores de Guimarães lamentaram o facto de os escudeiros do infante $\mathrm{D}$. Henrique terem requisitado aos aquantiados em armas da cidade uma série de arneses com que D. Fernando de Bragança, Gonçalo Pereira e outros combatentes haveriam de servir no ataque a Ceuta, espólio esse que nunca lhes tinha chegado a ser devolvido, contrariamente ao que fora estipulado (IHES, FLUC, Col. Cortes, Cortes de Lisboa de 1427, Capítulos Especiais de Guimarães, n. ${ }^{\circ}$ 2, fl. $175 v^{\circ}{ }^{\circ}$ ).

Convém também notar que houve lugar à aquisição de armas em Inglaterra (apesar de ali estar em marcha a campanha que desaguaria na famosa batalha de Agincourt), pois, meio ano antes da partida da frota lusitana, João Vaz de Almada recebeu autorização de Henrique $V$ para levar para o rei de Portugal 400 lanças, enquanto, meses depois, o seu filho Álvaro Vaz (o futuro «conde de Avranches») obteve autorização do mesmo monarca para equipar seis homens de armas com outros tantos arneses e para adquirir em Inglaterra 350 lanças para serviço do rei de Portugal, com dispensa de todos os direitos (M. Henr, II, 36: 94-95, de Westminster 26-09-1414; e id., 51: 123-124, de Westminster, 20-01-1415).

Completando o rol das armas que seguiram a bordo da armada que zarpou de Santa Catarina no dia de São Tiago, o cronista refere - ao descrever os preparativos para o ataque, ensaiados a bordo dos navios na madrugada do próprio dia 21 de agosto de 1415 - com quanto entusiasmo se pregavam os arneses, se experimentavam as atacas dos gibões (para verificar se eram suficientemente fortes), se brandiam as fachas (achas-de-armas, ou seja, armas de choque da mesma família das maças e dos martelos de armas), se sacavam das bainhas e se agitavam no ar as espadas, observando se o seu gume se anunciava capaz de ferir os mouros (C. T. Ceuta, LXVIII: 193). Se a tudo isto acrescentarmos as centenas ou milhares de escudos que, com toda a certeza, seguiam a bordo (e a que o próprio espião ao serviço da Coroa aragonesa alude, como vimos), então teremos uma lista bastante completa e previsível (tendo em conta o padrão europeu coevo) das armas defensivas e ofensivas que viajaram com el-rei para o Norte de África naquele verão quente de 1415 . 
Resta-me analisar a questão (bem complexa) da planificação e execução tática da campanha. $O$ primeiro aspeto a considerar tem que ver com o comando da expedição. Uma vez que o monarca seguia a bordo, não restam dúvidas de que a liderança da campanha lhe pertenceu. Ao seu lado, seguiam praticamente todas as figuras gradas da corte ou do regime, como os três infantes legítimos mais velhos (Duarte, Pedro e Henrique), o conde de Barcelos (D. Afonso, também ele filho de D. João I), o condestável (D. Nuno Álvares Pereira), o marechal (Gonçalo Vasques Coutinho), o alferes-mor (João Gomes da Silva), o almirante, o capitão-mor, os mestres de Cristo e de Santiago, o prior do Hospital, diversos altos funcionários régios (a começar pelo vedor da Fazenda, João Afonso de Alenquer, a quem Zurara atribui a sugestão do ataque a Ceuta - IX: 27), a generalidade das principais figuras das Casas dos infantes (como o governador da Casa de D. Henrique, Vasco Fernandes de Ataíde, uma das poucas baixas fidalgas no combate de Ceuta), o anadel-mor dos besteiros de cavalo (Afonso Anes de Cernache), entre muitas outras pessoas respeitáveis. Em terra parece ter ficado apenas, entre os notáveis, o mestre de Avis, Fernão Rodrigues Sequeira, amigo pessoal e antigo aio do monarca, incumbido da preciosa tarefa de garantir a segurança do reino e a dos infantes mais novos (João e Fernando).

A composição desta armada tem surpreendido historiadores de várias gerações pela sua rara qualidade: se acaso as coisas corressem mal durante a viagem marítima ou no ataque à praça magrebina, o reino - acabado de sair de uma guerra muito desgastante com Castela - poderia ficar em maus lençóis (Saraiva 1988: 242; Duarte 2015: 96, 108) ... Adivinha-se, portanto, que os índices de confiança eram elevados e que tudo foi feito para garantir que o monarca seguisse o mais bem acompanhado possível. Tendo em conta a autoridade de D. João I e a sua larga experiência militar (sobretudo em operações de cerco, nas quais, pelas minhas contas, deve ter consumido quase 600 dias da sua vida entre 1384 e 1400, de Tuy a Campo Maior, ou de Lisboa a Coria e a Alcántara), seria de esperar que as decisões do monarca fossem inquestionáveis. E, no entanto, não é essa a imagem que frequentemente transparece da leitura da Crónica da Tomada de Ceuta: apesar de rodeado do núcleo duro formado por aqueles que o acompanhavam desde o início da sua saga rumo à conquista do poder (no célebre conselho de Torres Vedras, em 1414, o rei terá lembrado que "todos os que aqui estaaes fostes comigo naquelles meus primeiros trabalhos" - XXVI: 80 ), várias das opiniões do monarca foram contestadas nos sucessivos conselhos régios realizados antes, durante e depois da conquista da praça; em especial para o que aqui mais nos importa - na reunião decisiva realizada a 19-20 de agosto na Ponta do Carneiro, perto de Algeciras, durante a qual o monarca marcou a ofensiva final para o dia seguinte e impôs um plano de ataque que não terá sido do agrado de muitos dos seus conselheiros (id., LXII-LXIV: 181-187). O 
que é que mais pode ter contribuído para esta reiterada divisão de opiniões no seio do conselho de guerra joanino (a fazermos fé na narrativa de Zurara)? Em meu entender, talvez a veterania de alguns dos seus companheiros os pusesse mais à vontade para contraditar as opiniões do monarca; ou talvez a impaciência e o ardor de muitos dos mais novos (a começar pelos infantes Duarte, Pedro e Henrique) os colocassem com frequência em rota de colisão com as estratégias supostamente mais ponderadas e cautelosas do velho rei.

Este ponto é importante, tanto mais que o decurso da operação parece confirmar algum conflito entre aquilo que foi programado e o que se verificou no terreno. Destacarei apenas dois aspetos particularmente ilustrativos. Por um lado, e como já referi, D. João I apostou fortemente no secretismo da operação, certamente como forma de garantir um efeito surpresa máximo na hora de concretizar o ataque a Ceuta. Todavia, a frota portuguesa atravessou o estreito de Gibraltar e ancorou na baía de Algeciras no dia 10 de agosto, apenas tendo atacado em força a grande cidade merínida onze dias mais tarde - a 21 de agosto de 1415! Parece seguro afirmar-se que esta décalage - que deitou por terra qualquer aspiração de apanhar os muçulmanos completamente de surpresa - se ficou sobretudo a dever às dificuldades de navegação, que fizeram abortar um primeiro movimento ofensivo lançado no dia 12 de agosto, criando uma situação quase caricata: durante quatro ou cinco dias (até reagrupar em Algeciras a 16 de agosto), a frota lusitana andou 'entre Cila e Caríbdis', com as naus a serem por duas vezes arrastadas para nascente, na direção de Málaga (devido ao nevoeiro e aos ventos), enquanto o grosso da armada sob o comando do rei tentava, sem sucesso, substituir a sua primeira posição a norte de Ceuta (12 de agosto) por uma concentração de recurso mais a sul, no ancoradouro de Barbaçote, dois dias mais tarde (Monteiro e Costa 2015: 42-47).

Podemos muito bem argumentar não ser legítimo imputar a D. João I (que, de resto, não tinha qualquer experiência da guerra marítima) grandes responsabilidades por este primeiro insucesso, que a natureza e as reconhecidamente difíceis condições de navegabilidade no estreito podem por si sós explicar. Mas não deixa de ser chocante perceber a forma como este revés parece ter abalado a confiança de muitos dos expedicionários (para além de ter tranquilizado os muçulmanos, criando-lhes talvez a ilusão de que o ataque teria abortado): se Zurara não fugiu muito à verdade, no conselho realizado poucos dias depois na Ponta do Carneiro, muitos houve que terão advogado um regresso imediato a Portugal, enquanto outros defenderam a construção de um projeto alternativo, que poderia bem passar por um ataque a Gibraltar (C.T. Ceuta, LXII-LXIV: 181187).

O rei não aceitou nenhuma das possibilidades, e com toda a lógica: não tinha consumido vários anos de esforços a preparar uma campanha daquela magnitude para depois regressar a casa com o rabo entre as pernas, ou exibindo apenas 
como troféu o rochedo de Gibraltar (o que, ainda por cima, lhe poderia causar graves dissabores diplomáticos com Castela). Assim, o monarca agendou o ataque decisivo para o dia seguinte e impôs o seu próprio plano de ataque: a frota dividir-se-ia, com o infante D. Henrique (ao comando dos barcos que reunira no Porto) a aproximar-se da Almina e a ancorar na praia de Santo Amaro, na zona nordeste do istmo (a parte residencial e mais fortemente amuralhada da praça). Enquanto isso, o monarca, com o resto da armada, fingiria tomar o rumo da baía sul (Barbaçote), com o objetivo manifesto de dividir as forças muçulmanas e de as levar a acreditar que o grosso da armada portuguesa desembarcaria por esse lado. Quando tal sucedesse, o rei daria um sinal e D. Henrique e os seus homens tratariam de lançar as pranchas em terra e de ocupar a praia de Santo Amaro, a eles se juntando depois, tão depressa quanto o possível, o resto da armada. Deste modo, o ataque português concentrar-se-ia todo ele sobre a porta da Almina, na zona nordeste da cidade, esperando-se que fosse depois possível avançar para poente, através das ruas interiores da praça (ib.).

Este plano contrariava a vontade de vários dos conselheiros régios, que preferiam uma ofensiva sobre a outra banda da cidade, onde se poderiam organizar e defender melhor, graças à abertura de fossos e à instalação dos artifícios de cerco que transportavam a bordo. Contudo, como bem observou o general Loureiro dos Santos (2004: 80-81), o rei deve ter querido evitar dividir as suas forças, e não quis correr o risco de ser obrigado a enfrentar, simultaneamente (e tal como sucederia 22 anos mais tarde ao infante D. Henrique no inferno de Tânger), os Mouros que residiam em Ceuta e aqueles que supostamente acorreriam do exterior, pelo lado do continente, para defenderem a sua amada praça.

Ora, se o plano do monarca parece compreensível, já a sua execução dá que pensar. É que, sempre segundo o cronista, os homens não suportaram a espera pelo sinal do rei: a certa altura, João Fogaça, vedor do conde de Barcelos, mandou o seu batel avançar para a praia de Santo Amaro. Num ápice, os homens que seguiam a bordo começaram a desembarcar, seguindo o exemplo do futuro comendador de Santiago, Rui Gonçalves. Ao ver isto, o infante D. Henrique receoso, talvez, de ficar para trás - meteu-se também ele num batel e avançou com o seu alferes (Mem Rodrigues de Refoios) e com outros dos seus homens para a praia. Ao aperceber-se, ao longe, do que se estava a passar, o infante D. Duarte optou por abandonar o grosso da frota, que seguia com o rei, para se juntar ao irmão. De repente, na praia de Santo Amaro, já havia uma centena e meia de cristãos a travarem as primeiras escaramuças com os Mouros. Estes, sem os conseguirem conter, recuaram na direção da Porta da Almina. No entanto, era já tarde demais, pois muitos outros cristãos tinham entretanto chegado à praia; por isso, os infantes, em lugar de esperarem pelo pai, acharam que o melhor seria correrem atrás dos muçulmanos e impedi-los de cerrarem a Porta da Almina. Se bem o pensaram, melhor o fizeram: ao final da manhã, três centenas de cris- 
tãos entraram de roldão pela dita passagem e penetraram no arrabalde, frisando Zurara que o primeiro que assim o fez terá sido Vasco Martins de Albergaria. Com os infantes, introduziram-se no arrabalde da Almina perto de 500 combatentes, frustrando dessa maneira o plano de defesa da cidade, que aparentemente consistia em travar os cristãos assim que estes pisassem a praia, tirando partido da sua suposta menor mobilidade, devido ao peso dos arneses que envergavam. Pouco a pouco, a frota do rei alcançou, toda ela, a praia de Santo Amaro e os homens foram desembarcando e foram-se juntando-se, cada qual ao ritmo que podia e que queria, aos demais companheiros no ataque à cidade (Monteiro e Costa 2015: 60-63).

$\mathrm{O}$ que se seguiu foi uma luta de rua pura e dura, muito ao sabor das circunstâncias do momento, uma espécie de Estalinegrado em versão medieval e marroquina, em que os únicos imperativos táticos parecem ter sido, por um lado, a divisão em três colunas (julgo que para mitigar o congestionamento e cobrir os diversos arruamentos da urbe) e, por outro, a ocupação dos pontos altos, para ganharem vantagem no combate direto e para evitarem expor-se ao despejo, pelos muçulmanos, de projéteis de todo o tipo (setas, lanças, pedras, entre outros). Este ambiente, que se prolongou desde o início até ao final da tarde (Zurara afirma que cerca das 19h30 estava tudo consumado - LXXXVII: 234), pode ter sido propício à prática de façanhas marciais por parte de muitos cristãos (e o cronista aproveita para destacar o caso do infante D. Henrique, sobre o qual centra agora descaradamente a sua narrativa), mas nada de bom sugere quanto ao rigor tático da operação! Em boa verdade, se as coisas aconteceram deste modo, o plano fixado na Ponta do Carneiro foi totalmente desprezado, o desembarque foi feito precipitadamente e à revelia do rei, que se viu desautorizado pelos seus próprios filhos no momento mais delicado da campanha...

Não deixa de ser paradoxal este desfecho, que só não trouxe dissabores suplementares porque a defesa da praça se mostrou surpreendentemente débil: o alcaide Salah ibn Salah fugiu cedo (talvez logo que soube que os cristãos tinham conseguido forçar a entrada na cidade - ib., LXXXIII: 226), o socorro do rei de Fez não chegou a tempo (ao que parece, nem "ao atar das feridas", como diria Fernão Lopes) e a população de Ceuta (talvez já bastante diminuída desde que percebera, nos dias anteriores, que iria ser atacada por uma armada poderosa) ficou entregue a si própria. Aparentemente, tendo sido ocupado sem qualquer resistência o castelo (onde os cristãos só encontraram um simpático biscainho e um genovês!), apenas o combate pela posse da poderosa torre de Fez, no extremo poente da cidade, parece ter sido verdadeiramente penoso, até que ali se conseguiu hastear, já ao lusco-fusco, a bandeira do infante D. Duarte (ib., LXXXVI : 232-233).

Este contraste entre uma operação bem planeada e uma execução algo precipitada e um pouco de improviso, apesar da veterania do comandante da armada 
e de muitos dos seus companheiros, serve afinal para travar o nosso entusiasmo e para nos lembrar que estamos ainda a falar de um exército tipicamente medieval, sem treino regular conjunto, sem comando profissional e onde a tentação da bravata cavaleiresca está sempre presente e condiciona muitas vezes os resultados, geralmente influenciando-os de forma negativa, como foi há anos claramente demonstrado por Claude Gaier (2009: 119-136).

No caso da operação em apreço, devido ao tamanho do exército, ao ardor dos assaltantes e à fragilidade da resistência muçulmana, o ataque acabou por redundar num sucesso fulgurante, provavelmente muito acima das expetativas iniciais (tendo até em conta a quantidade de material de cerco que fora transportada a bordo e que nem sequer precisou de ser instalada). Mas, logo na discussão que se seguiu - acerca de manter ou não a cidade -, bem como na escolha do futuro capitão da praça, voltamos a ter a sensação de um comando dividido e de projetos pouco consolidados, se não mesmo algo contraditórios.

Nada que nos deva surpreender. Esta hoste real que conquistou Ceuta era ainda, em muitos aspetos, filha das hostes que tinham consumado a reconquista portuguesa entre meados do século XII e meados do século XIII. Jogavam agora num cenário diferente, mas combatiam o mesmo tipo de adversário e souberam adaptar-se facilmente a isso e a todas as circunstâncias envolventes. Se analisarmos o que foi a guerra na região de Ceuta nas décadas que se seguiram (pelo menos até 1458, o ano em que aquela cidade deixou de ser um enclave português em África e passou a ter a companhia de Alcácer Ceguer), percebemos que as técnicas e as táticas militares utilizadas pelo astuto capitão D. Pedro de Meneses e pelos seus sucessores são extremamente parecidas com as da guerra contra a mourama na finisterra portuguesa: ataques de surpresa, golpes de mão fulgurantes, movimentos noturnos, criação de áreas tampão à volta da cidade, elevado nível de espionagem e de contra-espionagem, instalação de atalaias nos pontos altos, recurso a sinos de alarme, vigilância exaustiva (até com recurso a galgos levados pela trela), repartição de despojos (o famoso "quinto das cavalgadas"), troca de prisioneiros, manobras de intimidação psicológica, complemento de operações terrestres com ações marítimas, etc ${ }^{6}$.

Só num particular esta peleja se diferenciou claramente da guerra da Reconquista: nos primeiros tempos, em Ceuta, os cristãos não dispunham de cavalos... A fidalguia sentiu profundamente essa limitação e, aos poucos, tratou de mandar vir (ou mesmo de transportar) para a praça norte-africana um conjunto de montadas: começaram por ser 14, vindas de Castela (Zurara, C. T. Ceuta,

6 Acerca da defesa de Ceuta sob o comando de D. Pedro de Meneses (1415-1437), é fundamental ver-se outra narrativa de Zurara, a Crónica do Conde D. Pedro de Meneses. Veja-se também, com muito proveito, Duarte, 2003: 409-417. Deve ver-se ainda a interessante biografia do conde D. Pedro assinada por Campos, 2008. 
XVI: 55-56) e terão talvez chegado a um máximo de uma ou duas centenas de animais. Na companhia desses fiéis companheiros, esta nova terra de fronteira (sinónimo de risco, mas também de oportunidades) ganhou outra alegria e pôde converter-se num palco muito apetecível para a fidalguia mais aguerrida e mais sequiosa de obter pelas armas a glória e o proveito que não lhe chegavam por outras vias. É curioso recordar que Ceuta, na primeira metade do século XV, foi procurada por portugueses e por nobres de outros reinos (por exemplo, por Aragoneses e Catalães) para palco dos seus feitos de armas, para as suas batalhas a ultranza, que eram verdadeiros duelos de armas que o Conde D. Pedro de Meneses arbitrava com a sabedoria e a autoridade que todos lhe reconheciam (Monteiro 1998: 438-439).

Ao mesmo tempo, "a guerra de Ceuta" (não apenas a da conquista do verão de 1415, mas sobretudo a da manutenção da praça pelos anos fora) constituiu uma autêntica 'escola' que ajudou a forjar a expansão ultramarina portuguesa. Como tem sido salientado pelos historiadores (Monteiro e Costa: 171; Duarte: 240), houve uma Casa de Ceuta em Lisboa, antes da Casa da Índia; houve uma "carreira de Ceuta", antes da "carreira da Índia"; houve toda uma geração de homens que circulou durante muitos anos pelo "mar do meio" para garantir a manutenção (contestada, mas nunca renunciada) de uma conquista que teve, pelo menos, o mérito de iniciar um novo caminho para Portugal. É extraordinário, comovente mesmo, que este feito tenha sido ainda iniciado e liderado por aqueles que - de cabelos "ruços" e membros já castigados pelo peso de cinco a seis décadas de uma vida dura e cheia de perigos - tinham estado também juntos, trinta anos antes, no campo de batalha de São Jorge-Aljubarrota. Grande geração, esta, e grande legado!

\section{Bibliografia}

\section{Fontes}

Chancelarias Portuguesas, D. João I. Lisboa: Centro de Estudos Históricos da Universidade Nova de Lisboa, 2006, Volume III, Tomo 3.

Cortes Portuguesas: Reinado de D. Afonso V (1439). Edição preparada por João José Alves Dias e Pedro Pinto; Transcrições de Carlos Silva Moura e Pedro Pinto. Revisão de João José Alves Dias e Pedro Pinto. Lisboa: Centro de Estudos Históricos da Universidade Nova de Lisboa, 2016.

Instituto de História Económica e Social, Faculdade de Letras da Universidade de Coimbra, Coleção de Cortes.

LOPES, Fernão, Crónica del Rei dom João I da boa memória. Parte Segunda, ed. de W. Entwistle. Lisboa: Imprensa Nacional-Casa da Moeda, 1977. 
Monumenta Henricina, dir. e org. de A. J. Dias Dinis. Coimbra: Comissão Executiva das Comemorações do V Centenário da Morte do Infante D. Henrique, 1960-1974 (16 vols.).

Ordenações Afonsinas, apresentação de M. J. Almeida e Costa, nota textológica de E. Borges Nunes. Lisboa: Fundação Calouste Gulbenkian, 1984 (5 vols.).

ZURARA, Gomes Eanes de, Crónica da Tomada de Ceuta por el-Rei D. João I, edição de F. M. Esteves Pereira, Academia das Ciências de Lisboa: 1915.

ZURARA, Gomes Eanes de, Crónica do Conde D. Pedro de Meneses, apresentação de J. A. de Freitas Carvalho, Porto, Programa Nacional de Edições Comemorativas dos Descobrimentos Portugueses: 1988.

\section{Estudos}

BRAGA, Isabel D., BRAGA, Paulo D. (1998), Ceuta Portuguesa (1415-1465). Ceuta: Instituto de Estudios Ceutíes.

CAMPOS, Nuno Silva (2008), D. Pedro de Meneses. O primeiro capitão de Ceuta. Lisboa: Sete Caminhos.

DUARTE, Luís Miguel (2003), “A guerra em Marrocos: aprender tudo de novo”, in Manuel Themudo Barata e Nuno Severiano Teixeira (dir.), Nova História Militar de Portugal. Lisboa: Círculo de Leitores, 2003, vol. I (coord. de José Mattoso).

DUARTE, Luís Miguel (2015). Ceuta 1415. Seiscentos anos depois. Lisboa: Livros Horizonte.

FARIA, Tiago Viúla de (2013), The Politics of Anglo-Portuguese Relations and their Protagonists in the Later Middle Ages (c.1369-c.1449). D. Phil. Thesis: University of Oxford.

FARO, Jorge de (1965), Receitas e Despesas da Fazenda Real de 1384 a 1481 (Subsídios documentais). Lisboa: Publicação do Centro de Estudos Económicos.

GAIER, Claude, “Témérité et bravade chevaleresques: une composante tactique embarrassante", Revista de História das Ideias, n. ${ }^{\circ}$ 30, 2009.

MONTEIRO, João Gouveia (1998). A Guerra em Portugal nos finais da Idade Média. Lisboa: Editorial Notícias.

MONTEIRO, João Gouveia, COSTA, António Martins (2015). 1415. A conquista de Ceuta. Lisboa, Manuscrito.

MONTEIRO, João Gouveia, MARTINS, Miguel Gomes, FARIA, Tiago Viúla de (2017). "Another 1415: Portugal's Military Landscape at the Time of Agincourt", Journal of Medieval History, Volume 43 (Special Issue: «Agincourt in context: war on land and sea». Guest editors: Rémy Ambühl and Craig Lambert).

RUSSELL, Peter E. (2000), A intervenção inglesa na Península Ibérica durante a Guerra dos Cem Anos. Trad. port., Lisboa, Imprensa Nacional - Casa da Moeda (ed. orig. 1955).

SANTOS, José Loureiro dos (2004), Ceuta, 1415. A conquista. Lisboa, Tribuna.

SARAIVA, António José (1988), O crepúsculo da Idade Média em Portugal. Lisboa: Gradiva. 